
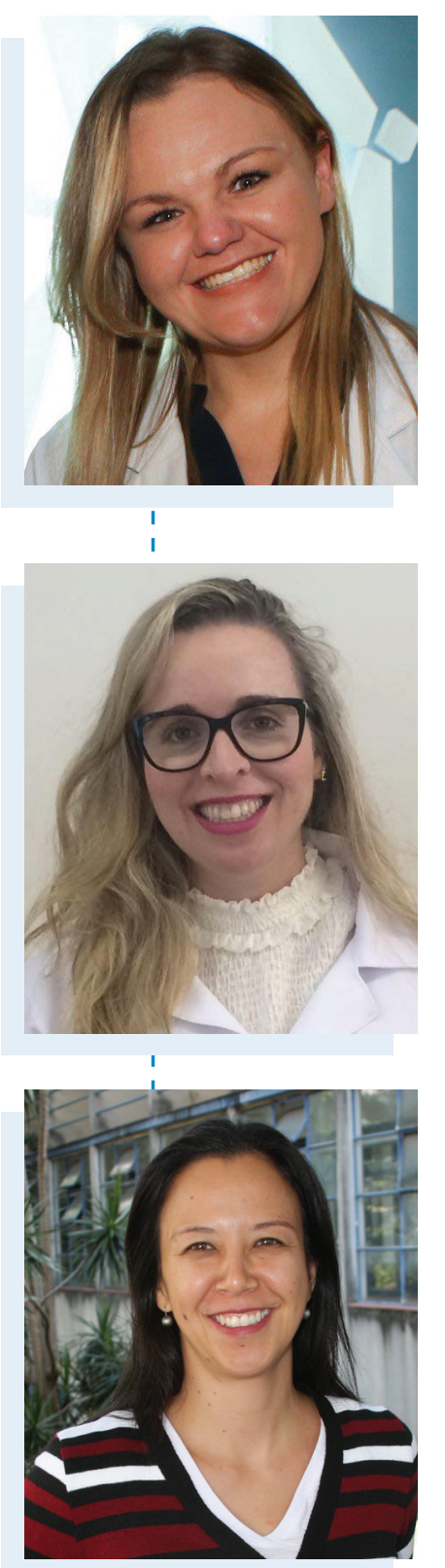

1.Hospital Sírio Libanês - Serviço de Estomaterapia - São Paulo (SP), Brasil.

2.Universidade Federal do Espírito Santo - Departamento de Enfermagem - Vitoria (ES), Brasil.

3.Universidade de São Paulo - Escola de Enfermagem - Departamento de Enfermagem Médico-Cirúrgica - São Paulo (SP), Brasil.

*Autor correspondente: alineo_ramalho@hotmail.com

Lesão por pressão relacionada a dispositivo médico nos profissionais de saúde em época de pandemia

\author{
Medical Device-Related Pressure Injury in health care \\ professionals in times of pandemic
}

\section{Lesión por presión relacionada a un dispositivo médico en los profesionales de la salud en época de pandemia}

Aline de Oliveira Ramalho ${ }^{1,3, *}$, Paula de Souza Silva Freitas ${ }^{2}$, Paula Cristina Nogueira ${ }^{3}$

\section{ORCID IDs}

Ramalho AO DiD https://orcid.org/0000-0001-6065-5488 Freitas PSS (D) https://orcid.org/0000-0001-9066-3286 Nogueira PC (D) https://orcid.org/0000-0001-5200-1281
Diante do número de casos de infecção pelo coronavírus (COVID-19), a Organização Mundial da Saúde (OMS) declarou que a doença se trata de uma pandemia de alerta e mobilização mundial, estando presente em vários países e continentes ${ }^{1}$.

No Brasil, a pandemia chegou no final de fevereiro de 2020 e vem causando alerta pelo aumento no número de contaminados relacionado com a alta capacidade de transmissão da doença. Nos doentes acometidos, o vírus pode causar desde sintomas simples, que podem ser tratados em casa, até internações hospitalares, assistência em unidades de terapia intensiva e pode inclusive levar à morte ${ }^{2}$.

Frente a essa pandemia, os profissionais que prestam assistência aos pacientes com suspeita ou confirmação de infecção pela COVID-19 constituem uma população de alto risco de contágio. Dessa forma, medidas preventivas tais como higiene adequada das mãos e utilização de equipamentos de proteção individual (EPI) vêm sendo reforçadas.

Dentre os EPIs, as máscaras de proteção respiratória, do tipo N95 e similares, devem ser utilizadas para realização de procedimentos que gerem aerossóis, tais como: intubação, ventilação não invasiva, aspiração e outros cuidados. Além disso, a Sociedade de Medicina Intensiva recomenda a utilização constante dessa proteção em ambientes de terapia intensiva que atendem pacientes com confirmação e/ou suspeita de COVID-193.

A OMS reconhece a necessidade da utilização de máscara de proteção respiratória, porém chama a atenção para que esta não seja utilizada por um período maior que 4 h seguidas, devido

\section{COMO CITAR}

Ramalho AO; Freitas PSS; Nogueira PC. Lesão por pressão relacionada a dispositivo médico nos profissionais de saúde em época de pandemia. ESTIMA, Braz. J. Enterostomal Ther., 18: e0120; 2020. https://doi.org/10.30886/ estima.v18.867_PT 
ao incômodo decorrente da sua utilização. No entanto algo vem chamando a atenção dos enfermeiros, especialmente dos estomaterapeutas, que são as lesões por pressão relacionadas a dispositivo médico ${ }^{4,5}$ causadas pelo uso da máscara N-95. Frequentemente temos visto em mídias sociais ${ }^{6}$ a divulgação de fotos (Figs. 1 e 2) de profissionais de saúde com lesões de pele na área de aplicação desse $\mathrm{EPI}^{7}$.
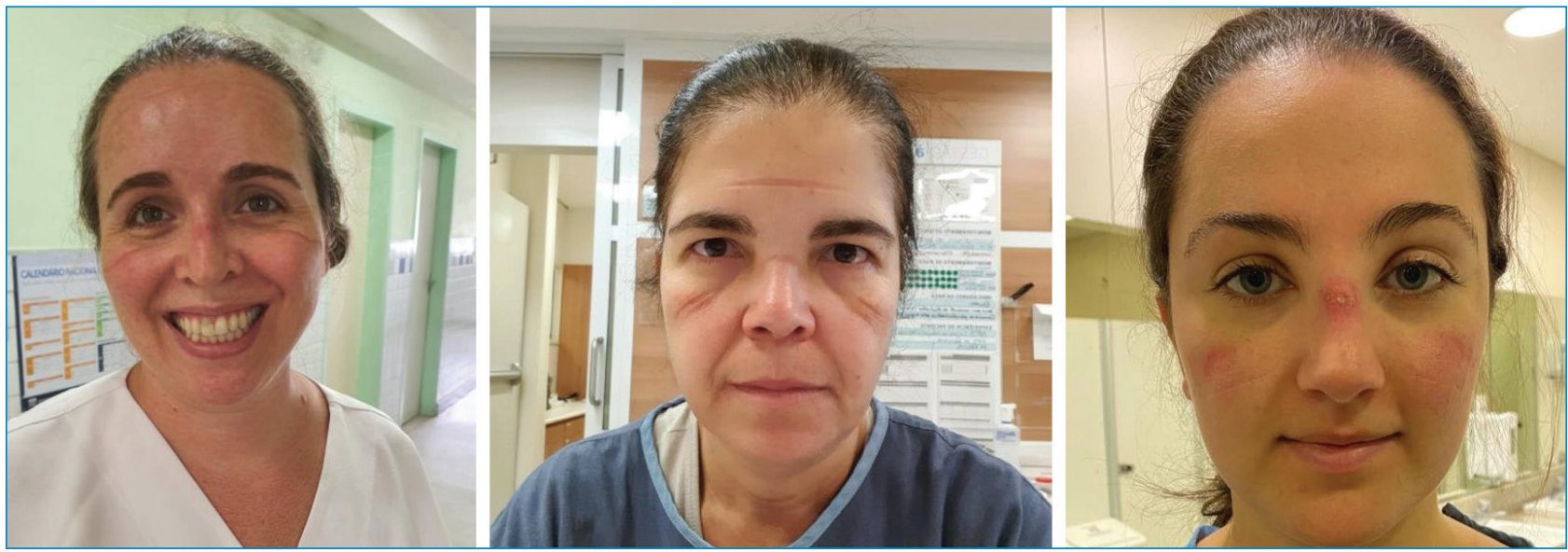

Figura 1. Profissionais brasileiras com LP relacionada ao uso de máscara. Imagens publicadas com autorização.
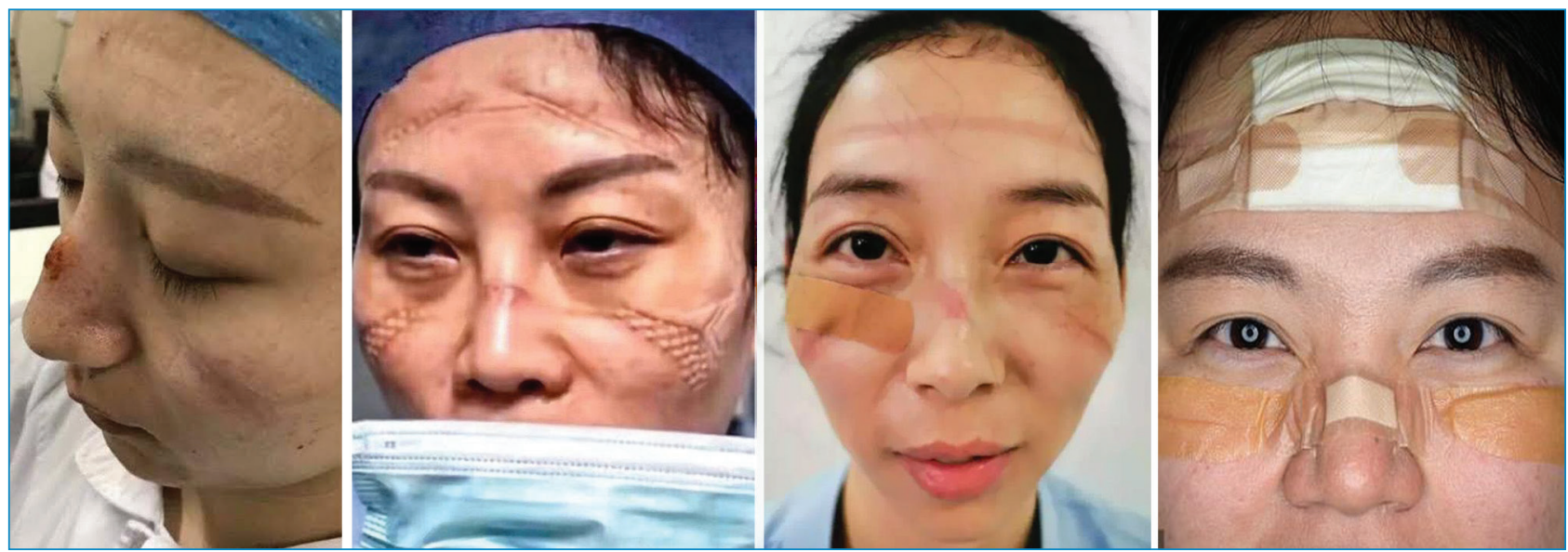

Figura 2. Imagens de profissionais da saúde chinesas com lesões por pressão causadas por EPIs. ${ }^{6}$

As lesões por pressão relacionadas a dispositivos médicos ${ }^{4,5}$ vêm ganhando destaque na pesquisa nacional e internacional, especialmente por sabermos que os dispositivos utilizados no cuidado à saúde por muitas vezes são indispensáveis, cabendo então a implementação de diretrizes que auxiliem na preservação da integridade da pele, na área exposta ao risco.

Todavia, até aqui, as orientações tem sido direcionadas aos pacientes que estão sob nossos cuidados, porém, frente às demandas atuais, é fundamental voltarmos a atenção também para a manutenção da integridade da pele do profissional, uma vez que a ocorrência da lesão pode causar impactos na assistência, na qualidade de vida e na autoestima, bem como apresentar-se como porta aberta para infecções.

Pensando nisso, algumas recomendações que em geral são direcionadas e realizadas para o cuidado aos pacientes, podem ser aplicadas também aos profissionais da saúde em uso de máscaras respiratórias e outros EPIs, a fim de contribuir com a manutenção da pele íntegra ${ }^{8,9}$ :

- Higienizar a pele com sabonete líquido, de preferência com pH compatível com a pele (levemente acidificado) e hidratar a pele com produto cosmético (creme hidratante) sem presença de lipídeos;

- Aplicar uma cobertura profilática como interface entre a pele e a área de fixação da máscara (quando esta for utilizada por um longo período, especialmente na região do zigomático e osso nasal), tais como: espuma de poliuretano fina, silicone, filme transparente ou placas de hidrocoloide extrafino; 
- Programar minutos de alívio de pressão, mediante possibilidade de retirada da máscara, a cada 2 h;

- Inspecionar a pele frequentemente e atentar-se à sinais de dor, desconforto, hiperemia e lesões;

- Evitar colocar a máscara e outros EPIs sobre áreas de lesões de pele, eczema ou hiperemia, sem o devido tratamento tópico prévio.

Os profissionais de saúde, especialmente a equipe de enfermagem, são mundialmente reconhecidos pelo heroísmo, pela luta e abnegação em cuidar de si mesmo para cuidar dos outros. No entanto é fundamental que o autocuidado impere nesse momento de pandemia, pois é necessário que os profissionais estejam com sua saúde preservada para colaborarem com um cuidado efetivo para a sociedade.

\section{AGRADECIMENTOS}

As autoras agradecem a colaboração do Grupo de Pesquisa em Estomaterapia: estomas, feridas agudas e crônicas e incontinências urinária e anal, da Escola de Enfermagem da Universidade de São Paulo (GPET-EEUSP).

\section{REFERÊNCIAS}

1. World Health Organization (WHO). Rational use of personal protective equipment for coronavirus disease 2019 (COVID-19): Interim guidance. Genebra: WHO; 2020. [citado em 21 mar 2020]. Disponível em: https://apps.who.int/iris/bitstream/ handle/10665/331215/WHO-2019-nCov-IPCPPE_use-2020.1-eng.pdf

2. Monteiro N, Aquino V, Pacheco S, Scheneiders L. Saúde anuncia orientações para evitar a disseminação do coronavírus. Brasil: Ministério da Saúde; 2020. [citado em 21 mar 2020]. Disponível em: https://www.saude.gov.br/noticias/agencia-saude/46540saude-anuncia-orientacoes-para-evitar-a-disseminacao-do-coronavirus

3. Associação de Medicina Intensiva Brasileira (AMIB). Na UTI, a segurança da equipe é fundamental! São Paulo: AMIB; 2020. [Citado em 21 mar 2020]. Disponível em: https://www.amib.org.br/fileadmin/user_upload/amib/2020/marco/07/COVID-19_seguranca_ equipev14032020_18h16.pdf

4. National Pressure Ulcer Advisory Panel (NPUAP). National Pressure Ulcer Advisory Panel (NPUAP) announces a change in terminology from pressure ulcer to pressure injury and updates the stages of pressure injury. Washington: Wound Source; 2016. [citado em 21 mar 2020]. Disponível em: https://www.woundsource.com/blog/national-pressure-ulcer-advisory-panel-npuapannounces-change-in-terminology-pressure-ulcer

5. Caliri MHL, Santos VLCG, Mandelbaum MHS, Costa IG. Classificação das Lesões por pressão - Consenso NPUAP 2016 - Adaptada Culturalmente para o Brasil. São Paulo: SOBEST/SOBENDE; 2016. [citado em 21 mar 2020]. Disponível em: http://www.sobest.org. $\mathrm{br} /$ textod/35

6. Mills J. Medics left with sore marks all over their skin from coronavirus face masks. Londres: Metro; 2020. [citado em 21 mar 2020]. Disponível em: https://metro.co.uk/2020/02/05/medics-left-sore-marks-skin-coronavirus-face-masks-12188952/

7. Utaraite N. Chinese nurses share pictures of how their faces look after countless hours fighting the coronavirus. Bored Panda. [citado em 26 mar 2020]. Disponível em: https://www.boredpanda.com/chinese-nurses-face-masks-corona-virus/?utm_ source=google\&utm_medium=organic\&utm_campaign=organic

8. Gefen A, Alves P, Ciprandi G, Coyer F, Milne CT, Ousey K, et al. Device-related pressure ulcers: SECURE prevention. J Wound Care. 2020;29(Sup2a):S1-52. https://doi.org/10.12968/jowc.2020.29.Sup2a.S1

9. European Pressure Ulcer Advisory Panel; National Pressure Injury Advisory Panel; Pan Pacific Pressure Injury Alliance. Prevention and Treatment of Pressure Ulcers/Injuries: Clinical Practice Guideline - The International Guideline. EPUAP/NPIAP/PPPIA. 2019. 